Rabaska

Revue d'ethnologie de l'Amérique française

\title{
Prix, honneurs, distinctions
}

\section{Lisette Comeau}

Volume 9, 2011

URI : https://id.erudit.org/iderudit/1005913ar

DOI : https://doi.org/10.7202/1005913ar

Aller au sommaire du numéro

Éditeur(s)

Société québécoise d'ethnologie

ISSN

1703-7433 (imprimé)

1916-7350 (numérique)

Découvrir la revue

Citer ce document

Comeau, L. (2011). Prix, honneurs, distinctions. Rabaska, 9, 247-250.

https://doi.org/10.7202/1005913ar

Ce document est protégé par la loi sur le droit d'auteur. L'utilisation des services d'Érudit (y compris la reproduction) est assujettie à sa politique d'utilisation que vous pouvez consulter en ligne.

https://apropos.erudit.org/fr/usagers/politique-dutilisation/
Cet article est diffusé et préservé par Érudit.

Érudit est un consortium interuniversitaire sans but lucratif composé de l'Université de Montréal, l'Université Laval et l'Université du Québec à Montréal. Il a pour mission la promotion et la valorisation de la recherche. https://www.erudit.org/fr/ 


\section{Prix, honneurs, distinctions}

LisetTe COMEAU

Université Sainte-Anne

\section{Prix Philippe-Aubert-de-Gaspé}

Cette année, en novembre 2010, le Salon du livre de la Côte-du-Sud a remis le prix littéraire Philippe-Aubert-de-Gaspé à l'ethnologue JEAN SIMARD afin de souligner son importante contribution au patrimoine, notamment par la production de nombreux livres portant sur l'iconographie, l'art populaire, la religion populaire et le patrimoine religieux. Né à Québec en 1941, le lauréat est détenteur d'un baccalauréat en pédagogie de l'Université Laval, d'un baccalauréat en philosophie de l'Université de Montréal, d'une licence ès lettres en histoire de l'Université Laval et d'un doctorat en sciences historiques de l'Université de Strasbourg en France. À la suite de ses études, il a enseigné l'ethnologie du Québec et des francophones en Amérique du Nord à l'Université Laval de 1972 à 2000. Ses travaux lui ont déjà mérité plusieurs distinctions : la médaille Luc-Lacourcière en 1990, accordée par le CÉLAT de l'Université Laval à l'auteur du meilleur ouvrage sur l'ethnologie des francophones en Amérique du Nord, et le prix Marius-Barbeau en 2005, attribué par l'Association canadienne d'ethnologie et de folklore, pour souligner l'excellence de sa carrière d'ethnologue ; il est entré à la Société des Dix en 1991 et a joint la Société royale du Canada en 1995. Maintenant à la retraite, Jean Simard vient de terminer son mandat de président de la Société québécoise d'ethnologie et il est secrétaire du comité de rédaction de Rabaska depuis les débuts de cette revue.

Source : www.oieblanc.com

\section{Prix Mnémo 2010}

Pour une dixième fois, le Centre Mnémo a attribué sa récompense annuelle à « une production jugée remarquable dans le domaine de la documentation ou de la recherche relative à la danse, à la musique, à la chanson et au conte traditionnel des francophones d'Amérique ». Le jury du prix Mnémo a révélé le nom des lauréats et remis cet honneur le 4 décembre 2010, à Montréal, à 
Raynald Ouellet, Denis Pépin et Christian Maes pour leur double album intitulé John. J Kimmel - Un héritage fabuleux. Ces trois accordéonistes ont créé un album en hommage au maître de l'accordéon diatonique John J. Kimmel (1866-1942), qui est connu comme pionnier de l'enregistrement sur disque et dont la première production date de 1903. Cette véritable légende de la musique traditionnelle continue d'exercer une influence incontestée sur les musiciens des nouvelles générations. Le trio, qui a créé un album double accompagné de notes biographiques, a brillamment réussi à tracer un portrait fidèle de l'œuvre et des réalisations de ce grand musicien, et à les mettre en valeur.

Source : www.mnemo.qc.ca

\section{Prix Gérard-Morisset 2010}

Le prix Gérard-Morisset est la distinction la plus prestigieuse attribuée par le Gouvernement du Québec dans le domaine du patrimoine. Ayant consacré l'ensemble de sa carrière au patrimoine, François-Marc Gagnon en est le récipiendaire pour l'année 2010. Né à Paris en 1935, il fait un séjour de douze ans dans les ordres, chez les dominicains, puis commence sa carrière comme professeur de philosophie à l'École des beaux-arts de Montréal au début des années 1960. En 1966, il prend un poste au département d'histoire de l'art de l'Université de Montréal. Par la suite, la Sorbonne lui remet un doctorat en histoire de l'art en 1972. La même année, François-Marc Gagnon publie le premier de ses trois livres maîtres, soit La Conversion par l'image : Un aspect de la mission des Jésuites auprès des Indiens du Canada au XVII ${ }^{e}$ siècle. Il se mérite le prix du Gouverneur général en 1978 pour son deuxième livre Paul-Émile Borduas (1905-1960) : Biographie critique et analyse de l'cuvre. Enfin, il publie son troisième livre intitulé Chronique du mouvement automatiste québécois, 1941-1954 en 1998 pour lequel il se mérite le prix Raymond-Klibansky l'année suivante. Après avoir passé 34 années au département de l'histoire de l'art et avoir mérité à deux reprises un prix d'excellence en enseignement, François-Marc Gagnon prend sa retraite de l'Université de Montréal en 2000. Depuis, il dirige l'Institut de recherche en art canadien Gail et Stephen A. Jarilowsky à l'Université Concordia et donne des séries de conférences au public du Musée des beaux-arts de Montréal. Il travaille également à rassembler les deux manuscrits attribués au jésuite Louis Nicolas, soit le Codex canadiensis et Histoire naturelle des Indes occidentales. Le prix Gérard-Morisset lui a été remis le 9 novembre 2010 à l'Assemblée nationale du Québec.

Source : www.prixduquebec.gouv.qc.ca 


\section{Médaille Luc-Lacourcière 2009}

Le 6 novembre 2009, le Centre interuniversitaire d'études sur les lettres, les arts et les traditions (CÉLAT) a remis la Médaille Luc-Lacourcière 2009 à Madeleine Pastinelli pour son ouvrage Des souris, des hommes et des femmes au village global. Parole, pratiques identitaires et lien social dans un espace de bavardage électronique. Publié aux Presses de l'Université Laval en 2007, ce livre propose une plongée dans l'univers social et relationnel d'une communauté de bavardage électronique, dans laquelle l'ethnologue a fait enquête pendant deux ans. La médaille Luc-Lacourcière, attribuée une fois tous les deux ans par un jury indépendant constitué de professionnels de l'ethnologie, reconnaît la contribution de l'auteur d'un ouvrage ayant marqué le domaine de l'ethnologie, et publié en français en Amérique du Nord. Madeleine Pastinelli est professeur au département de sociologie de l'Université Laval et membre régulier du CÉLAT. Elle s'intéresse à l'identité et aux rapports d'altérité dans les pratiques sociales contemporaines, qu'elle a abordées dans des contextes aussi variés que l'espace électronique, les ménages de colocataires et les espaces de tourisme culturel en milieu autochtone.

Source : www.celat.ulaval.ca

\section{Doctorat honorifique à Luc Noppen}

Le 21 novembre 2010, Luc NopPen, professeur au département d'études urbaines et touristiques de l'École des sciences de la gestion à l'Université de Québec à Montréal (ÉSG-UQÀM), recevait un doctorat honoris causa de l'Université Jean-Monnet, à Saint-Étienne. On lui conféra ce grade «en reconnaissance de sa carrière exceptionnelle dédiée au service des milieux sociaux et culturels, à l'enseignement, à la recherche et à la formation de jeunes chercheurs en histoire de l'architecture, en urbanisme et en patrimoine ». Luc Noppen a d'abord enseigné au département d'histoire et à l'École d'architecture de l'Université Laval de 1972 à 2001 avant de devenir le premier titulaire de la Chaire de recherche du Canada en patrimoine urbain à l'UQÀM. Premier directeur de l'Institut du patrimoine de 2005 à 2010, qui réunit une vingtaine de jeunes chercheurs, il est aussi l'auteur d'une trentaine de livres par lesquels il a contribué à définir, par la lecture originale qu'il en a propose, les fondements scientifiques de l'histoire de l'architecture du Québec. Il s'est toujours préoccupé de la sauvegarde du paysage construit et de la reconnaissance de l'originalité de l'environnement bâti québécois. Au fil des années, il s'est mérité plusieurs prix et distinctions, notamment Personnalité de la semaine du quotidien La Presse, la bourse de recherche 
Killam, le prix Thomas-Baillairgé de l'Ordre des architectes du Québec et le Prix Gérard-Morisset. Enfin, il est membre de la Société royale du Canada depuis une vingtaine d'années.

Source: www.nouvelles.uqam.ca 